\title{
'Primed' Mesenchymal Stem Cells: a Potential Novel Therapeutic for COVID19 Patients
}

\author{
Syed Shadab Raza ${ }^{1}$ (D) Pankaj Seth ${ }^{2} \cdot$ Mohsin Ali Khan $^{3}$ \\ Published online: 26 June 2020 \\ (C) Springer Science+Business Media, LLC, part of Springer Nature 2020
}

\begin{abstract}
The COVID19 pandemic, designated as a public health crisis by the World Health Organization (WHO), is rapidly spreading around the world impacting the health and economy of almost all the countries. The data of hospitalized COVID19 patients, especially those with serious illness, indicate the involvement of immunopathological complications. As no effective treatment is currently available, we propose 'Primed' Mesenchymal Stem Cells (MSCs) as a therapeutic alternative to tackle devastating epidemic. The individual response to MSCs treatment is heterogeneous. During the treatment of infectious pathology, the effectiveness of the treatment may vary based on the disease scenario. Interestingly, when transplanted in vivo, MSCs are governed by the locally regulated microenvironment, suggesting that the restorative variability could be tailored by choosing a priming regimen to specifically correct a given pathology. Therefore, in our opinion, the priming of MSCs could be a novel approach to improve the responses of COVID19 patients.
\end{abstract}

Keywords COVID19 $\cdot$ Coronavirus $\cdot$ SARS-CoV-2 $\cdot$ Mesenchymal stem cells $\cdot$ MSC priming $\cdot$ Immunomodulation

\section{Main}

Over the past 5 months, the coronavirus disease 2019 (COVID19) pandemic has relentlessly impacted the global population. The first case of COVID19 infection was identified in the Wuhan City of China on December 1, 2019. Since then, the virus has spread to 213 countries and territories, resulting in over 5.3 million confirmed cases and over 340,000 deaths as on May 23, 2020 (https://www. worldometers.info/coronavirus/). People of all ages are vulnerable to COVID19 infection; however, those over 60 years of age and with pre-existing medical conditions, such as cardiovascular disease, diabetes, or high blood pressure, are more prone to fall seriously ill and succumb to the disease. According to the Centers for Disease Control and Prevention,

Syed Shadab Raza

drshadab@erauniversity.in; drsyedshadabraza@gmail.com

1 Department of Stem Cell Biology and Regenerative Medicine, Era's Lucknow Medical College Hospital, Era University, Sarfarazganj, Lucknow 226003, India

2 Molecular and Cellular Neuroscience, Neurovirology Section, National Brain Research Centre, Manesar, Haryana 122052, India

3 Era's Lucknow Medical College Hospital, Sarfarazganj, Lucknow 226003, India the symptoms of COVID19 include fever, cough, and shortness of breath, fatigue and sudden loss of sense of smell and taste in some cases (https://www.cdc.gov/coronavirus/2019ncov/symptoms-testing/symptoms.html), though its typical characteristic is pneumonia that requires hospitalization and even death, if not intervened timely.

For any therapeutic intervention, the pathological cascade involved in a disease needs to be elucidated. Therefore, identifying the SARS-CoV-2 virus receptor recognition mechanism that regulates its virulence and pathogenesis holds the key to confront the COVID19 epidemic [1]. Structural analysis of SARS-CoV-2 revealed that the enveloped, positivesense, single-stranded RNA viruses belong to the genus $\beta$ coronavirus and have azoonotic origin [2]. Mounting evidence suggests that SARS-CoV-2 primarily spreads through the respiratory tract, either in the form of droplets, respiratory secretions, or direct contact [3]. In addition, the abundant presence of ACE2 protein receptor in lung alveolar epithelial cells facilitates the binding of SARS-CoV-2 spike-S-glycoprotein, and thus, expedites viral infection. This interaction also activates distinct cytokines crucial for antiviral responses. The data of critically severe COVID19 patients revealed the presence of IL-2, IL-6, IL-7, IL-10, TNF- $\alpha$, GCSF, MCP-1, MIP$1 \alpha$, and TNF- $\alpha$ [4] to name a few. To date, no specific approved antiviral therapy for the treatment of COVID19 infection is available, except standard supportive care e.g., 
oxygenation, ventilation, and fluid management, etc., and some non-specific treatments e.g., hydroxychloroquine and chloroquine etc., to ameliorate the symptoms, and some antivirals and protease inhibitors. Thus, to reverse or combat the detrimental effect produced by SARS-CoV-2 virus, there is an urgent need for a reliable therapy. In this context, multipotent mesenchymal stem cells (MSCs) have shown a strong safety and efficacy profile as they have been intensively investigated in preclinical and clinical studies of various lung diseases, including respiratory virus-induced acute respiratory distress syndrome (ARDS) [5, 6]. Over the past years, the MSCs infusion exhibited an excellent safety record as evident in the 871 clinical trials registered in the National Institute of Health database (https://clinicaltrials.gov/ct2/results?cond= Mesenchymal+Stem + Cells \& term $=\&$ cntry $=\&$ state $=\&$ city $=$ \&dist=), including 117 trials (https://clinicaltrials.gov/ct2/ results? cond $=$ mesenchymal + stem + cell\&term $=$ pulmonary $\&$ cntry $=\&$ state $=\&$ city $=\&$ dist $=\&$ Search $=$ Search $)$ on pulmonary complications, to date. On the other hand, 2845 COVID19 trials worldwide as of 23 May 2020 at World Health Organization-International Clinical Trial Registry Platform (https://www.who.int/ictrp/en/) and 29 clinical trials on MSCs and COVID19 as of 23 May 2020 (https:// clinicaltrials.gov/ct $2 /$ results? cond=mesenchymal + stem + cell\&term $=$ COVID $19 \&$ cntry $=\&$ state $=\&$ city $=\&$ dist $=$ $\&$ Search=Search) have been registered at the NIH database. Worth mentioning, that out of 29 clinical trials, one has been withdrawn (trial no. NCT04293692), therefore, as yet, 28 trials have been registered with a participation of approximately 1525 patients. All of the mentioned studies that employ MSCs and COVID19 patients are in earlyphase, and either recruiting or yet to recruit the participants.

To brief, out of the twenty-four clinical trials UC-MSCs will be utilized in eleven clinical trials, and AD-MSCs will be utilized in six trials, two will employ DPSCs, one with OM-MSCs, three on BM-MSC, and one (NCT04276987) will utilize exosomes derived from allogenic adipose mesenchymal stem cells, also the trail no. NCT043660663, with 60 participants, will be utilizing the MSC-derived exosomes in twenty participants (20/60), twenty will receive MSC only $(20 / 60)$, and the rest twenty will be treated as control (20/ 60). Four registries do not reveal the tissue source (Table 1). The minimum age eligibility criteria in all the trials are 18 years, except the trial no. NCT04349631, NCT04362189, and NCT03042143 where child, adult, or aged, all are eligible to get enrolled as participants. None of the above studies have gender restriction, and the minimum follow-up time is 3 months for each of these investigations. The above registries indicate that a majority of studies will employ umbilical cordderived MSC which seems reasonable for the following reasons: ease of harvest, fast doubling time, high scalability, and since umbilical cord has a high concentration of stem cells, they can provide a large amount of cells. Noteworthy they have faster doubling times, more plasticity, and with no tumorigenicity $[7,8]$. They are derived from a discarded tissue, and so have less ethical concern. In our opinion and experience, amongst the cell types used, equally desirable cell type for COVID19 patients is DPSCs, since they too appear to have similar advantages like UC-MSCs. Some of the unique advantages associated with DPSCs are noninvasive isolation, ease of harvest, and easy accessibility, as they reside in the impacted third molar; beside strong therapeutic ability are the key advantages of DPSCs [9]. They show clonogenicity, and higher ex-vivo proliferative capacity [10] compared with MSCs; they are less prone to malignancy [11], and therefore can give rise to sufficient numbers of cells for cell therapy. Compared with umbilical cord stem cells, DPSCs demonstrated delayed cellular senescence [12] which can be correlated to the increased expression of genes related to growth factors [13]. They have minimal ethical concerns, which is otherwise a hurdle often associated with other cell types. In the presence of specific stimuli, they can give rise to several cell types [14, $15]$. As per our knowledge, to date, there is only a single preclinical investigation [6], apart from a case report [16] that supports the rationale for the use of MSCs in COVID19. Interestingly, the Abu Dhabi Stem Cell Center (ADSCC), UAE has recently supervised a clinical trial on 73 COVID19 patients employing 'Activated' MSCs. The study claims that all the participants were successfully treatment and cured relieved of symptoms of the virus by inhaling the treatment into their lungs after it has been nebulized into a fine mist (https:// www.khaleejtimes.com/coronaviruspandemic/coronavirusuaes-stem-cell-treatment-fights-symptoms-of-covid-19-notcure-it-). The source of the MSCs was patients own blood. However, no further information has been provided, therefore, more detailed information regarding the procedure of stem cell processing and priming, dose and timing of MSCs inhalation, patients' age and gender, and the follow-up is needed to determine the efficacy of MSCs activation on those patients.

Interestingly, the data obtained from a single-center, openlabeled pilot investigation in COVID19 patients from China demonstrated that the treatment with MSCs improved diseaseassociated parameters in severe and critically severe patients [16]. To brief, seven patients (one critically severe, four severe, and two having common symptoms of pneumonia) were enrolled in the treatment group, where as three patients served as placebo controls (all displaying severe symptoms). All treated patients received a single dose of $1 \mathrm{X} 10^{6} \mathrm{MSCs} / \mathrm{kg}$ body weight. Remarkably, all seven showed improvement over two weeks with no noticeable adverse effect, thereby, demonstrated the safe and effective infusion of ACE2 $2^{-v e}$ MSCs in COVID19 pneumonia patients. The overall improvement in the MSCs infused group was striking as within 2 days after treatment pulmonary functions and symptoms of all the seven patients significantly improved, and most tested 


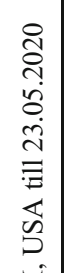

(

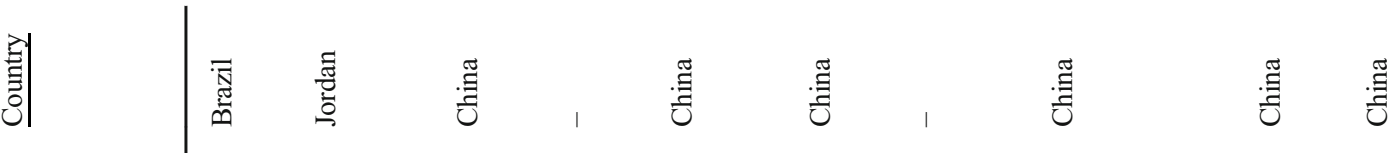

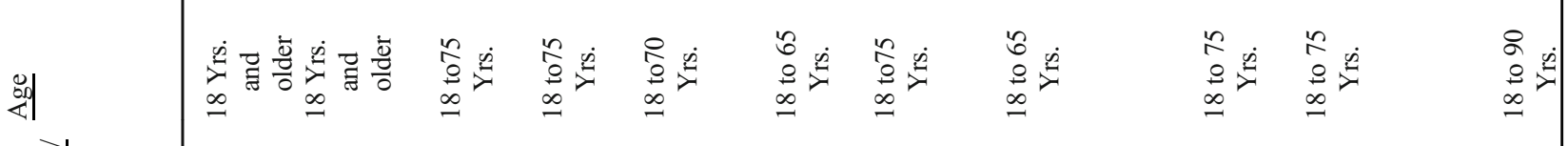

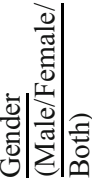

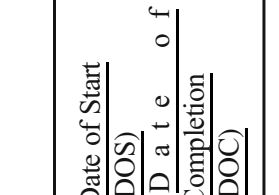

言言言言言言言

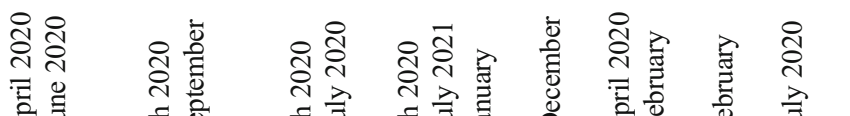

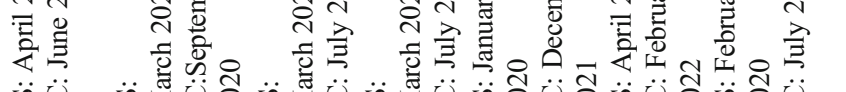

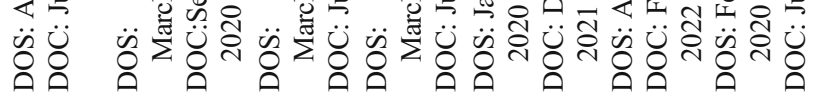

言

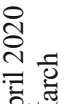

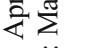

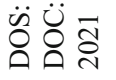

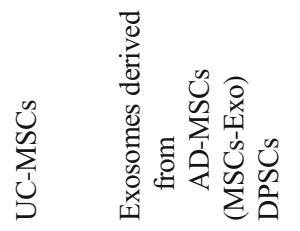

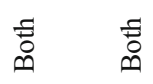

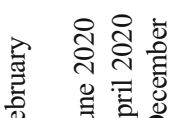

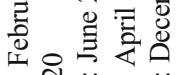

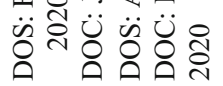

$\sum_{0}^{\infty} \quad \sum_{0}^{\infty}$

$\sum_{\substack{n \\ e}}^{\infty}$

离気|

苟

:

8

艺密

\& ำ

文

กิ

유

구

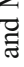

官

官

8

昜

.气.气

㐫

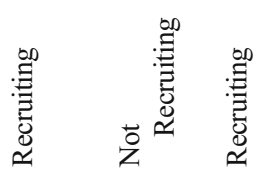

艺若

薯

艼
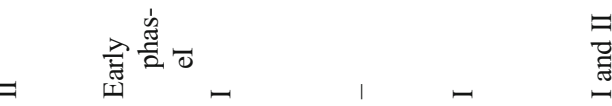

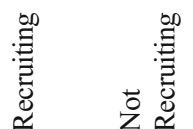

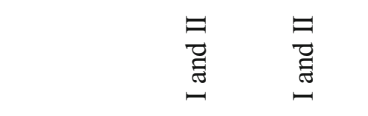

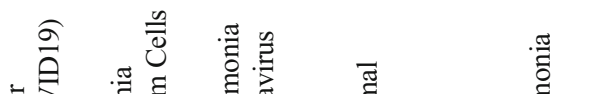

究

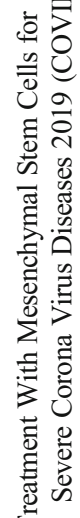

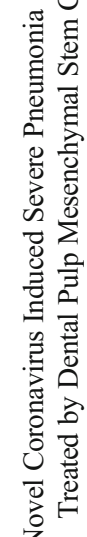

跣

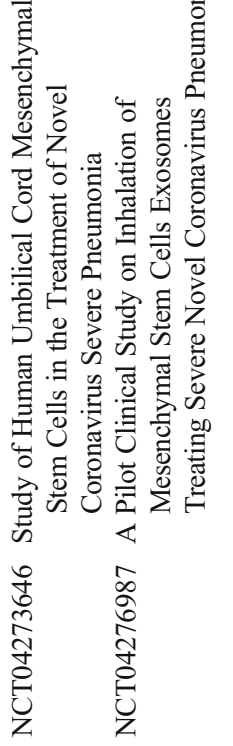

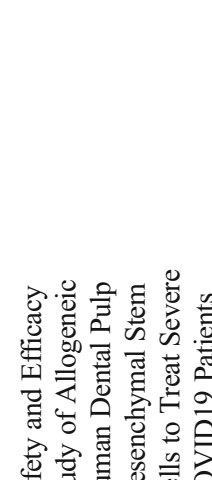

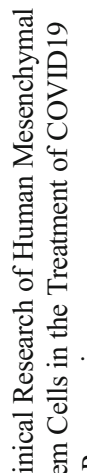

वे उँ

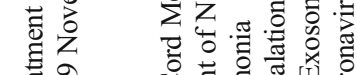

苞 令

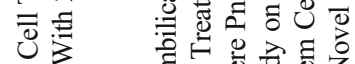

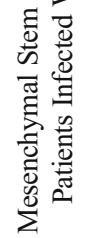

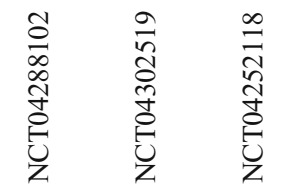

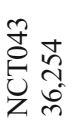

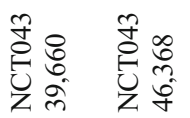

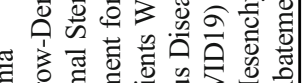

.

等

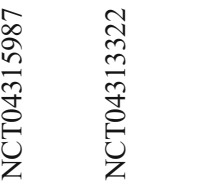




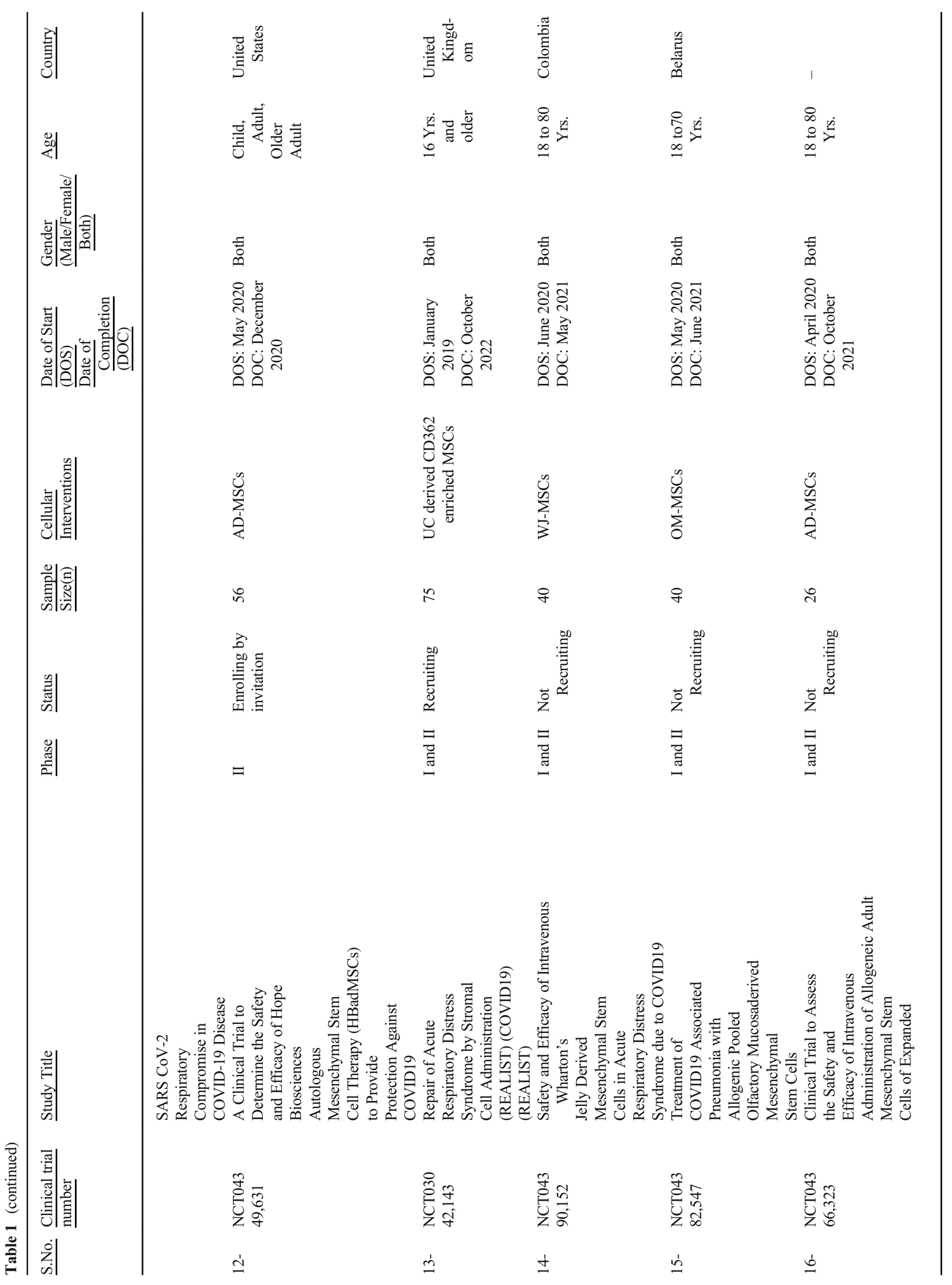




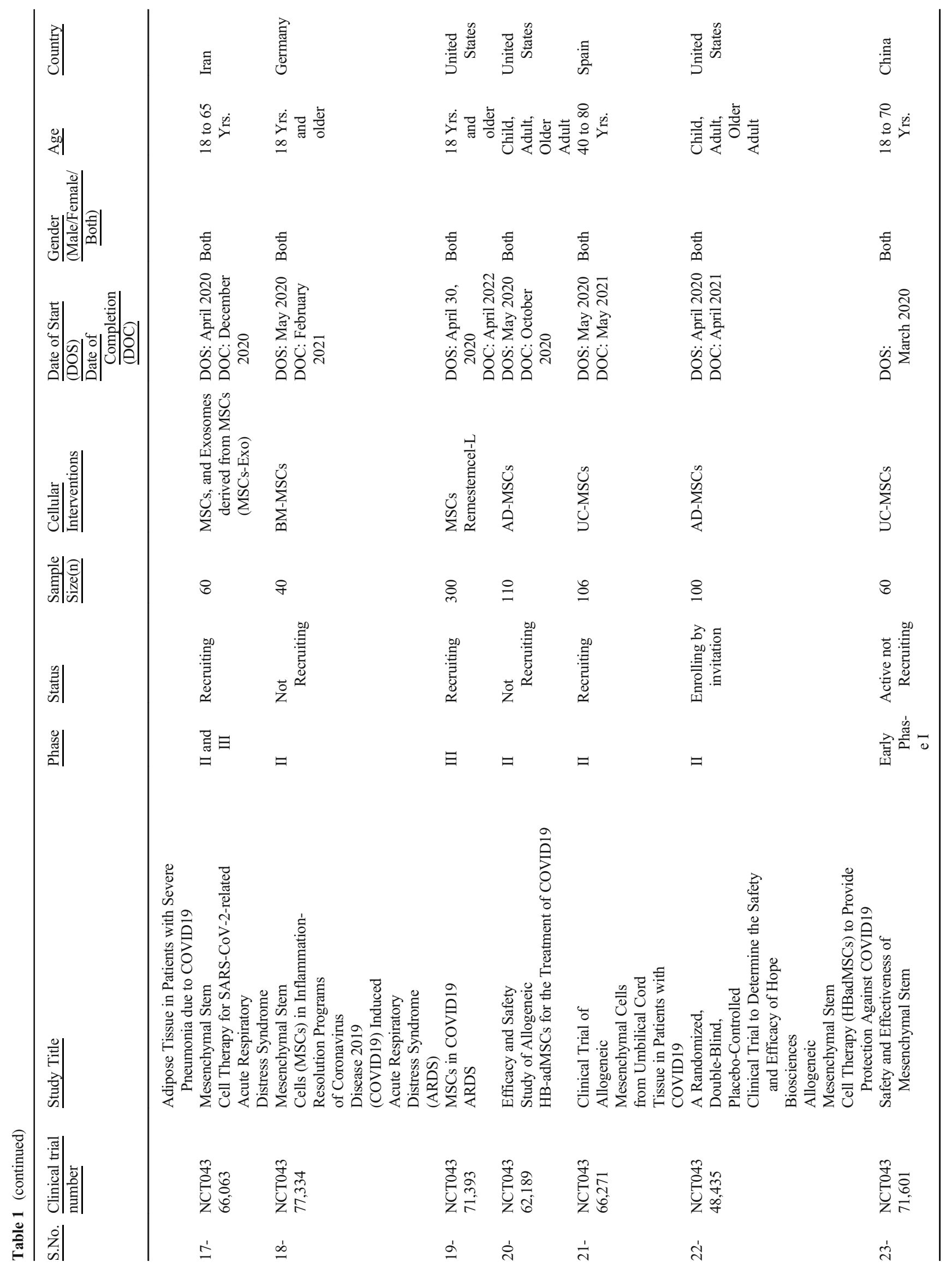




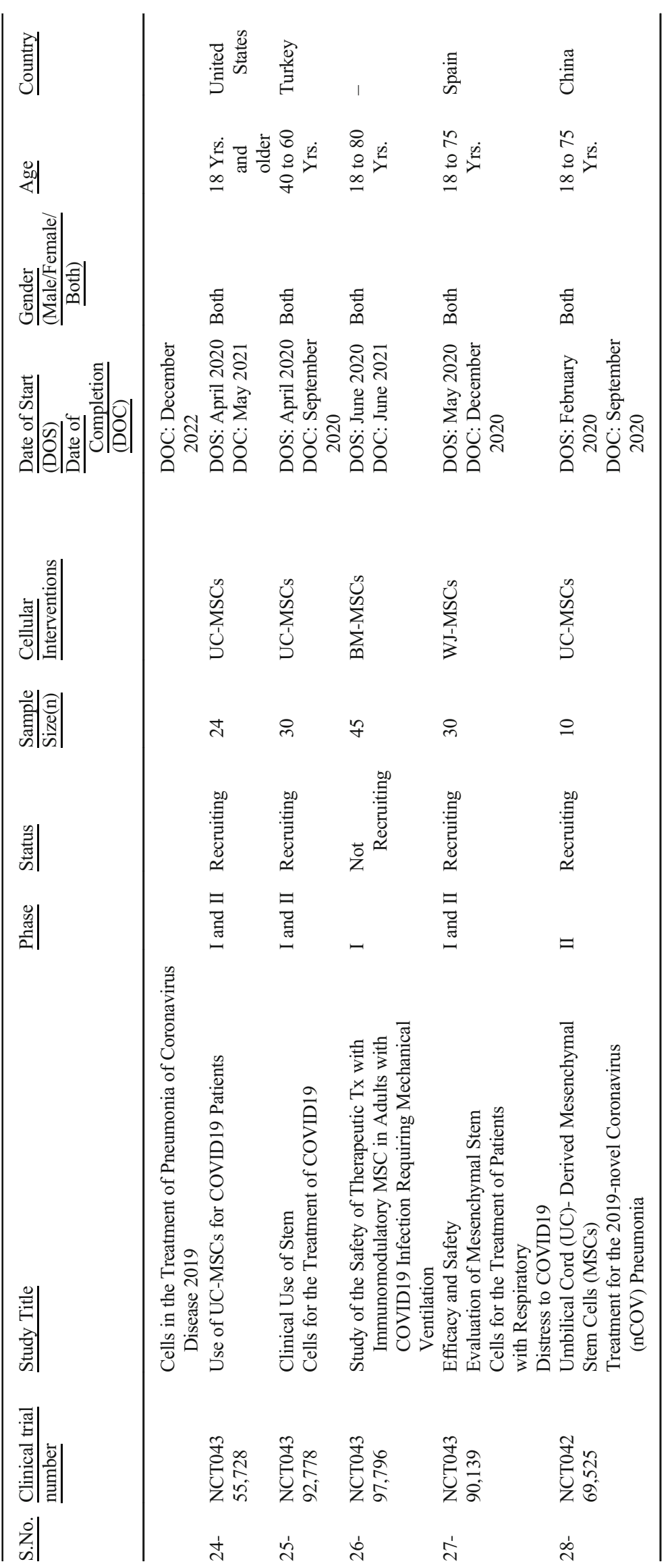


negative for the SARS-CoV-2 nucleic acid test over two weeks after MSCs infusion. After 6 days of infusion, the therapy inhibited the over-activation of the immune system by inhibiting $\mathrm{CXCR}^{+}{ }^{+} \mathrm{CD} 4^{+} \mathrm{T}$ cells, $\mathrm{CXCR}^{+}{ }^{+} \mathrm{CD} 8^{+} \mathrm{T}$ cells, and $\mathrm{CXCR}^{+}$NK cells. It also decreased TNF- $\alpha$ and enhanced the number of peripheral lymphocytes, $\mathrm{CD} 14^{+} \mathrm{CD} 11 \mathrm{c}^{+} \mathrm{CD} 11^{\text {bmid }}$ regulatory $\mathrm{DC}$, and antiinflammatory cytokine IL-10. Moreover, the gene expression profile revealed that MSC was ACE2 ${ }^{-\mathrm{ve}}$ and TMPRSS2 ${ }^{-\mathrm{ve}}$, which indicates that the MSCs would not be susceptible to SARS-CoV2 infection. Finally, the RNA sequencing and gene expression analysis showed that MSCs were closely involved in the anti-viral pathways, and had anti-inflammatory trophic activities [6]. In line with above findings, the results from a case report on COVID19 [16] and a study on influenza virus H9NA [5], which shares complications similar to COVID19 like ARDS and lung failure, demonstrated that MSCs can offer therapy for virally-induced pulmonary complications in clinical settings. While all these studies have provided new insights into the protective mechanism of MSCs during viral infection, a few short comings were noticed in these treatments. For example, similar to study conducted by ADSCC, there is also a lack of information on MSCs processing and screening before infusion, and the long-term follow-up of patients etc. For a protocol to be implicated in a larger cohort, optimal information regarding MSCs as well as patients needs to be investigated in a rationally designed controlled setting. Concerning the underlying mechanism by which MSCs exert a beneficial effect, the ability to home [17], engraft [17] and transdifferentiate into the target tissue, which is the infected lung in the present case, besides the bystander effect and immunomodulatory potential $[9,18,19]$, are well documented. Also, the anti-apoptotic, anti-viral, and anti-bacterial functions of this therapy have been well known [20]. Under homeostatic conditions, MSCs are hypo-immunogenic and have immune evasion capabilities [21], indicating their suitability for allogeneic transplantation.

Despite years of success in MSC research, some of the challenges faced for successful transplantation therapy include heterogeneous treatment response, low number, and sourcespecific immunomodulatory response [22]. Interestingly, the reparative effects noticed in vivo indicate that clinical efficacy depends on the microenvironment of the transplants [23]. Therefore, the therapeutic capability of MSCs can be regulated and is an attractive area for investigation. However, resting stage MSCs do not show the above potentials; it is only when they are exposed to a stimuli milieu, they demonstrate immunomodulatory or homing potentials $[24,25]$. This indicates that the modulatory activity is not constitutively expressed by MSCs but is determined by the process of 'priming' to be obtained. Therefore, the empowerment of MSCs by priming before a clinical application may be a potential solution to overcome the challenges that hinder the effectiveness of
MSC outcomes. Priming, with inflammatory cytokines, is a process to modulate biological, biochemical or biophysical features that can influence cell fate [26, 27]. In recent years, several approaches have been proposed to improve the effectiveness, endurance and therapeutic efficiency of MSCs [28, 29]. Worth mentioning, the approaches utilizing MSCs, and especially the primed MSCs, could be vital for the success of cell therapy in lung complications, as the intravenously infused MSCs often get trapped in the lung; however, the retention time of MSCs within the lung is extremely short [30]. Though, the alteration in holding capacity of lung in a diseased scenario cannot be ruled out. As primed MSCs could efficiently enhance retention [31], beside intensifying homing [17], and survival [32] in damaged lung, therefore, activation via priming could be a crucial mechanism for retention and engraftment of MSCs in a diseased lung, subsequently providing benefits to the lung through multiple mechanisms.

Priming perspectives and MSCs robustness are currently under development. Pre-treating MSCs before injection may enhance the expression of fitness markers and stimulate greater therapeutic outcome. For instance, reports suggest cytokine mediated activation of MSCs lead to strong immunosuppressive behavior, and thereby attenuation of lung injury in rodents [31,33], however some contradictory findings are also available as no effective role of proinflammatory cytokine priming was observed on MSCs in a model of acute lung injury and ARDS [34]. Therefore, the effect of cytokine priming needs to be further verified to prove the efficacy of primed MSCs in lung anomalies. Besides cytokines, priming of MSCs by growth factors is also a potent mechanism for MSC activation before infusion in pulmonary diseases [35]. Likewise, hypoxia preconditioning can also improve the proliferation and therapeutic efficacy of MSCs, as evident in bleomycin-induced pulmonary fibrosis model [36]. Further, employing pharmacological agents such as paclitaxel to prime MSCs could also be helpful in improving lung anomalies [37]. Therefore, in line with above findings it could reasonably by presume that MSC priming is a significant approach for treating pulmonary anomalies. In the light of above findings, herein, we propose that the mechanism of priming of MSC could be implied to the following: i) Licensing by proinflammatory cytokines such as IFN- $\gamma$, TNF- $\alpha$, etc., to enhance immunosuppressive potential; ii) Priming by noncytokines stimuli such as hormones/growth factors like HGF to boost defensive and protective cellular mechanisms; iii) Pre-conditioning by hypoxia, and/or pharmacological agents, e.g., sphingosine-1-phosphate, etc., to enhance engraftment and reparative effects; iv) Activation by spheroid culturing to enhance homing, survival, differentiation, and lineage specificity e.g. angiogenic mechanism; v) The timing of MSCs engraftment and engagement in the process of activation of immune cells to achieve the most excellent beneficial effect of MSCs infusion. 
Nevertheless, there are several limitations associated with the priming approaches that may jeopardize MSC based therapies at clinics; hence these challenges must be overcome to harness the true potential of MSCs. For instance, the priming of MSCs by proinflammatory cytokines may negatively affect the MHC class I and class II level; Hormones and/or growth factors may affect the differentiation capacity of MSCs; Priming by hypoxia may induce oxidative stress in MSCs; Growth factors may negatively affect the differentiation capacity of MSCs; Spheroid cultures owing to the variability in their size may lead to the necrotic spheroid core, thus, may interfere with the effectiveness of MSCs after transplantation. Further, the variations in results due to the heterogeneous
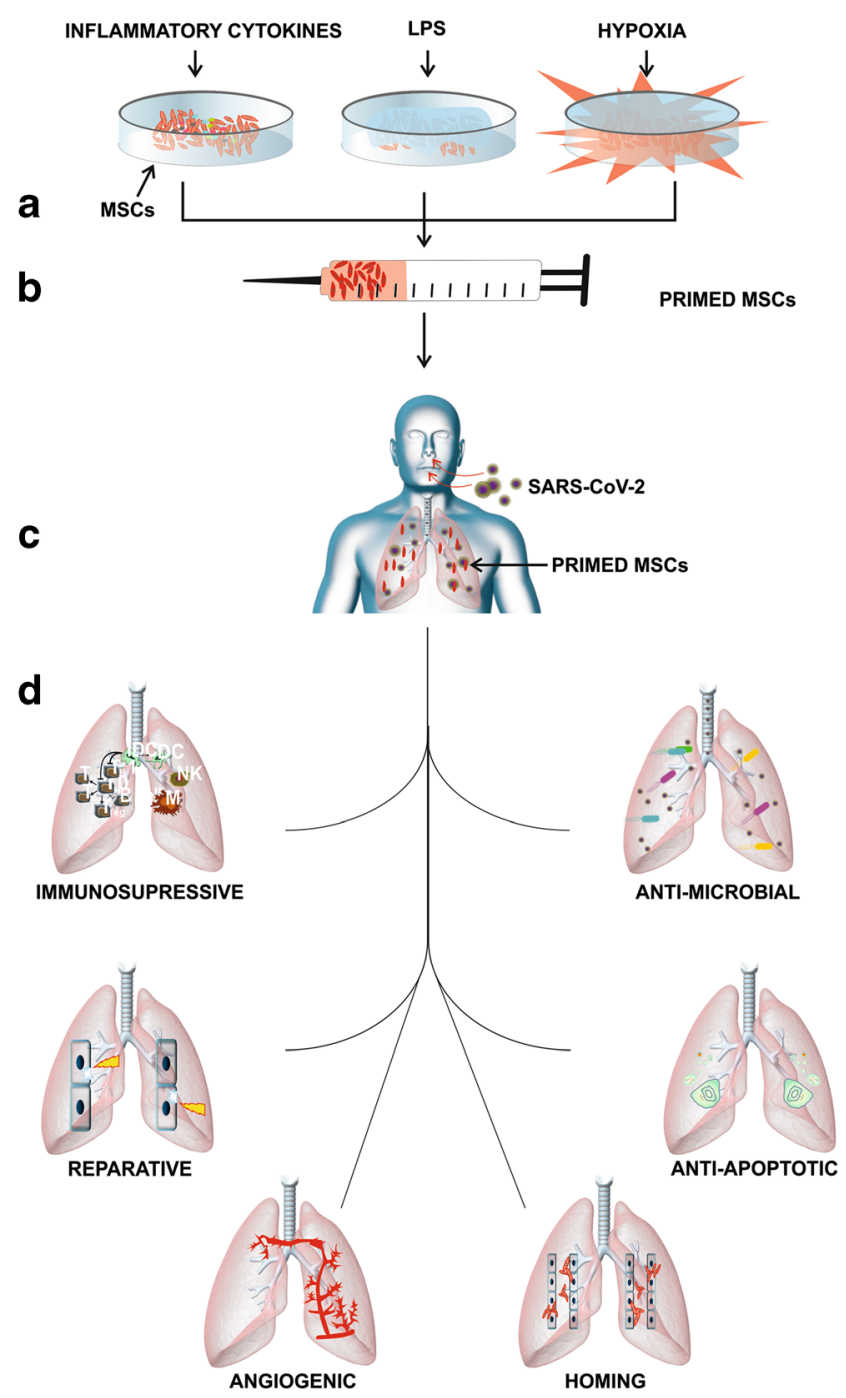

Fig. 1 Schematic of SARS-CoV-2 infecting lung epithelial cells, and priming approaches to improve MSCs therapeutic efficacy for the treatment of COVID19 patients. (a) Represent a few priming approaches (priming by inflammatory cytokines and LPS, hypoxia pre-conditioning, (b) Primed MSCs, (c) SARS-CoV-2 and 'Primed MSCs' post-infusion in the lung, (d) Therapeutic effect exerted by MSCs (immunosuppression, reparative, angiogenesis, homing, anti-apoptotic, and anti-microbial activities) nature of MSCs [23], and high cost associated with priming protocols, etc., are the considerable hindrances in the successful translation of primed MSCs to the clinic. For instance, not all the priming stimulus, even the same stimuli, shows a similar effect on the cells. Therefore, the effect of individual licensing stimuli should be accessed before being employed at a manufacturing scale. For example, IFN- $\gamma$ can inhibit $\mathrm{T}$ cell proliferation in the regulation of MSC-mediated immunosuppression [38] and can also increase the capacity of MSCs to produce different subtypes of Tregs [39]. IFN- $\gamma$ can also promote increased expressions of VCAM- 1 and ICAM- 1 on the surface of MSCs [40]. Similarly, the adjustment of MSC infusion timing may reveal the accurate description of inflammatory surroundings related to a specific disease [41]. This may also explain why MSCs do not always exhibit beneficial effects, even in the same disease. Therefore, it is of great importance to choose the right stimuli in the right dose at and for the right timing, besides fitness of MSCs, fresh vs. cryopreserved, MSCs passage number, and route of delivery to assure homogenous clinical outcomes (Fig. 1).

To conclude, since its emergence, COVID19 has turned out to be the top priority of the healthcare system. Although stem cell treatment has not yet been proven to eliminate coronavirus completely, preliminary results are promising, suggesting that the diseased patients, under the treatment, might be more amenable to survive the infection. The effect of priming on MSCs' therapeutic potential has been extensively researched and continues to be investigated. The results of such efforts are eagerly anticipated, as these will pave a way for a strong foundation for future scientific research and clinical applications for a variety of diseases including pulmonary complications. Finally, bearing in mind the desires for mitigation of the existing pandemic, the effectiveness of MSCs in virally infected acute respiratory diseases symptoms, and the pieces of evidence from priming strategies for MSCs, we hypothesize that endorsing priming may enhance the effectiveness of MSCs for long-term benefits which is a prerequisite for the success of stem cell therapy in COVID19 patients.

Acknowledgments We extend our thanks to Mr. Hari Shankar, Era University, for the precious suggestions and support in writing this manuscript.

Author Contributions SSR designed, drafted and edited the manuscript. PS and MAK reviewed the manuscript. All the authors have approved the final article.

Funding Information This research did not receive any specific grant from funding agencies in the public, commercial, or not-for-profit sectors.

\section{Compliance with Ethical Standards}

Disclosure of Competing Interest The authors declare no conflicts of interest. 
Abbreviations IL-2, interleukin 2; IL-6, interleukin 6; IL-7, interleukin 7; IL-10, interleukin 10; IFN- $\gamma$, Interferon gamma; TNF- $\alpha$, Tumor Necrosis Factor alpha; MCP-1, Monocyte Chemoattractant Protein 1; MIP-1 $\alpha$, Macrophage Inflammatory Proteins 1 alpha; GCSF, Granulocyte Colony Stimulating Factor; VCAM-1, Vascular Cell Adhesion Molecule-1; ICAM-1, Intracelullar Adhesion Molecule-1; HGF, Hepatocyte growth factor; BM-MSC, Bone Marrow derived Mesenchymal Stem Cell; AD-MSC, Adipose derived Mesenchyma 1 Stem Cell; UC-MSC, Umbilical Cord derived Mesenchymal Stem Cell; WJ-MSC, Warton Jelly derived Mesenchymal Stem Cell; OM-MSC, Olfactory Mucosa derived Mesenchymal Stem Cell; DPSC, Dental Pulp Stem Cell; NK Cells, Natural Killer Cells; DC, Dendritic Cells

\section{References}

1. Shang, J., Ye, G., Shi, K., Wan, Y., Luo, C., Aihara, H., Geng, Q., Auerbach, A., \& Li, F. (2020). Structural basis of receptor recognition by SARS-CoV-2. Nature, 30, 221-224. https://doi.org/10. 1038/s41586-020-2179-y.

2. Lu, R., Zhao, X., Li, J., Niu, P., Yang, B., Wu, H., Wang, W., Song, H., Huang, B., Zhu, N., Bi, Y., Ma, X., Zhan, F., Wang, L., Hu, T., Zhou, H., Hu, Z., Zhou, W., Zhao, L., Chen, J., Meng, Y., Wang, J., Lin, Y., Yuan, J., Xie, Z., Ma, J., Liu, W. J., Wang, D., Xu, W., Holmes, E. C., Gao, G. F., Wu, G., Chen, W., Shi, W., \& Tan, W. (2020). Genomic characterization and epidemiology of novel coronavirus: Implications for virus origins and receptor binding. Lancet, 395(10224), 565-574. https://doi.org/10.1016/S0140-6736(20) 30251-8

3. Guo, Y. R., Cao, Q. D., Hong, Z. S., Tan, Y. Y., Chen, S. D., Jin, H. J., Tan, K. S., Wang, D. Y., \& Yan, Y. (2020). The origin, transmission and clinical therapies on coronavirus disease 2019 (COVID-19) outbreak - an update on the status. Military Medical Research, 7(1), 11. https://doi.org/10.1186/s40779-020-00240-0.

4. Huang, C., Wang, Y., Li, X., Ren, L., Zhao, J., Hu, Y., Zhang, L., Fan, G., Xu, J., Gu, X., Cheng, Z., Yu, T., Xia, J., Wei, Y., Wu, W., Xie, X., Yin, W., Li, H., Liu, M., Xiao, Y., Gao, H., Guo, L., Xie, J., Wang, G., Jiang, R., Gao, Z., Jin, Q., Wang, J., \& Cao, B. (2020). Clinical features of patients infected with 2019 novel coronavirus in Wuhan, China. Lancet, 395(10223), 497-506. https://doi.org/10. 1016/S0140-6736(20)30183-5.

5. Chen, J., Hu C., Chen, L., Tang, L., Zhu, Y., Xu, X., Chen, Lu., Gao, H., Lu, X., Yu, L., Dai, X., Xiang, C., Li, L. (2020). Clinical study of mesenchymal stem cell treating acute respiratory distress syndrome induced by epidemic influenza a (H7N9) infection, a hint for COVID-19 treatment. Engineering (Beijing). https://doi.org/10. 1016/j.eng.2020.02.006

6. Leng, Z., Zhu, R., Hou, W., Feng, Y., Yang, Y., Han, Q., et al. (2020). Transplantation of ACE2-mesenchymal stem cells improves the outcome of patients with COVID-19 pneumonia. Aging Disease, 11, 216-228. https://doi.org/10.14336/AD.2020. 0228 .

7. Nagamura-Inoue, T., \& He, H. (2014). Umbilical cord-derived mesenchymal stem cells: Their advantages and potential clinical utility. World Journal of Stem Cells, 6, 195-202. https://doi.org/ 10.4252/wjsc.v6.i2.195.

8. Atluri, S., Manchikanti, L., \& Hirsch, J. A. (2020). Expanded umbilical cord Mesenchymal stem cells (UC-MSCs) as a therapeutic strategy in managing critically ill COVID-19 patients: The case for compassionate use. Pain Physician, 23(2), E71-E83.

9. Raza, S. S., Wagner, A. P., Hussain, Y. S., \& Khan, M. A. (2018). Mechanisms underlying dental-derived stem cell-mediated neurorestoration in neurodegenerative disorders. Stem Cell Research and Therapy, 9(1), 245. https://doi.org/10.1186/s13287018-1005-z.

10. Akiyama, K., Chen, C., Gronthos, S., \& Shi, S. (2012). Lineage differentiation of mesenchymal stem cells from dental pulp, apical papilla, and periodontal ligament. Methods in Molecular Biology, 887(41), 111-121. https://doi.org/10.1007/978-1-61779-860-3_11.

11. Wilson, R., Urraca, N., Skobowiat, C., Hope, K. A., Miravalle, L., Chamberlin, R., Donaldson, M., Seagroves, T. N., \& Reiter, L. T. (2015). Assessment of the tumorigenic potential of spontaneously immortalized and hTERT-immortalized cultured dental pulp stem cells. Stem Cells Translational Medicine, 4(8), 905-912. https://doi. org $/ 10.5966 / \mathrm{sctm} .2014-0196$.

12. Ren, H., Sang, Y., Zhang, F., Liu, Z., Qi, N., Chen, Y. (2016). Comparative analysis of human mesenchymal stem cells from umbilical cord, dental pulp and menstrual blood as sources for cell therapy. Stem Cells International, 2016 2016,3 516574. https:// doi.org/10.1155/2016/3516574.

13. Kang, C. M., Kim, H., Song, J. S., Choi, B. J., Kim, S. O., Jung, H. S., Moon, S. J., \& Choi, H. J. (2016). Genetic comparison of stemness of human umbilical cord and dental pulp. Stem Cells International, 2016, 3453890-3453812. https://doi.org/10.1155/ 2016/3453890.

14. Nuti, N., Corallo, C., Chan, B. M., Ferrari, M., \& Gerami-Naini, B. (2016). Multipotent differentiation of human dental pulp stem cells: A literature review. Stem Cell Review and Reports, 12(5), 511-523. https://doi.org/10.1007/s12015-016-9661-9.

15. Liu, J., Yu, F., Sun, Y., Jiang, B., Zhang, W., Yang, J., Xu, G. T., Liang, A., \& Liu, S. (2015). Concise reviews: Characteristics and potential applications of human dental tissue-derived mesenchymal stem cells. Stem Cells, 33(3), 627-638. https://doi.org/10.1002/ stem.1909.

16. Liang, B., Chen, J., Li, T., Wu, H., Yang, Li W.Y., Li, Y., Li, J., Yu, C., Nie, F., Ma, Z., Yang, M., et al. (2020). Clinical remission of a critically ill COVID19 patient treated by human umbilical cord mesenchymal stem cells, http://chinaxiv.org/abs/202002.00084.

17. Zhang, X., Chen, J., Xue, M., Tang, Y., Xu, J., Liu, L., Huang, Y., Yang, Y., Qiu, H., \& Guo, F. (2019). Overexpressing p130/E2F4 in mesenchymal stem cells facilitates the repair of injured alveolar epithelial cells in LPS-induced ARDS mice. Stem Cell Research Therapy, 10(1), 74. https://doi.org/10.1186/s13287-019-1169-1.

18. Fan, X. L., Zhang, Z., Ma, C. Y., \& Fu, Q. L. (2019). Mesenchymal stem cells for inflammatory airway disorders: Promises and challenges. Bioscience Reports, 39(1), BSR20182160. https://doi.org/ 10.1042/BSR20182160.

19. Ho, M. S., Mei, S. H., \& Stewart, D. J. (2015). The Immunomodulatory and therapeutic effects of Mesenchymal stromal cells for acute lung injury and sepsis. Journal of Cellular Physiology, 230(11), 2606-2617. https://doi.org/10.1002/jcp. 25028.

20. Meisel, R., Brockers, S., Heseler, K., Degistirici, O., Bulle”, H., Woite, C., et al. (2015). Human but not murine multipotent mesenchymal stromal cells exhibit broad-spectrum antimicrobial effector function mediated by indoleamine 2,3-dioxygenase. Leukemia, 25, 648-654. https://doi.org/10.1038/leu.2010.310.

21. Noronha, N. C., Mizukami, A., Caliari-Oliveira, C., Cominal, J. G., Rocha, J. L. M., Covas, D. T., et al. (2019). Priming approaches to improve the efficacy of mesenchymal stromal cell-based therapies. Stem Cell Research and Therapy, 10(1), 131. https://doi.org/10. 1186/s13287-019-1224-y.

22. Strioga, M., Viswanathan, S., Darinskas, A., Slaby, O., \& Michalek, J. (2012). Same or not the same? Comparison of adipose tissue-derived versus bone marrow-derived mesenchymal stem and stromal cells. Stem Cells and Development, 21(14), 2724-2752. https://doi.org/10.1089/scd.2011.0722. 
23. Szabó, E., Fajka-Boja, R., Kriston-Pál, É., Hornung, Á., Makra, I., Kudlik, G., Uher, F., Katona, R. L., Monostori, É., \& Czibula, Á. (2015). Licensing by inflammatory cytokines abolishes heterogeneity of immunosuppressive function of Mesenchymal stem cell population. Stem Cells Development, 24(18), 2171-2180. https:// doi.org/10.1089/scd.2014.0581.

24. Carvalho, A. E. S., Sousa, M. R. R., Alencar-Silva, T., Carvalho, J. L., \& Saldanha-Araujo, F. (2019). Mesenchymal stem cells immunomodulation: The road to IFN- $\gamma$ licensing and the path ahead. Cytokine and Growth Factor Reviews, 47, 32-42. https:// doi.org/10.1016/j.cytogfr.2019.05.006.

25. Ren, G., Zhang, L., Zhao, X., Xu, G., Zhang, Y., Roberts, A. I., Zhao, R. C., \& Shi, Y. (2008). Mesenchymal stem cell-mediated immunosuppression occurs via concerted action of chemokines and nitric oxide. Cell Stem Cell, 2(2), 141-150. https://doi.org/10.1016/ j.stem.2007.11.014.

26. Huang, C., Dai, J., \& Zhang, X. A. (2015). Environmental physical cues determine the lineage specification of mesenchymal stem cells. Biochemical Biophysical Acta, 1850, 1261-1266. https://doi.org/ 10.1016/j.bbagen.2015.02.011.

27. Nava, M. M., Raimondi, M. T., \& Pietrabissa, R. (2012). Controlling self-renewal and differentiation of stem cells via mechanical cues. Journal of Biomedicine and Biotechnology, 797410, 1-12. https://doi.org/10.1155/2012/797410.

28. Baldari, S., Di Rocco, G., Piccoli, M., Pozzobon, M., Muraca, M., \& Toietta, G. (2017). Challenges and strategies for improving the regenerative effects of mesenchymal stromal cell-based therapies. International Journal of Molecular Sciences, 18(10), 2087. https:// doi.org/10.3390/ijms18102087.

29. Kale, V. P. (2019). Application of "primed" Mesenchymal stromal cells in hematopoietic stem cell transplantation: Current status and future prospects. Stem Cells and Development, 28(22), 1473-1479. https://doi.org/10.1089/scd.2019.0149.

30. Armitage, J., Tan, D. B. A., Troedson, R., Young, P., Lam, K. V., Shaw, K., Sturm, M., Weiss, D. J., \& Moodley, Y. P. (2018). Mesenchymal stromal cell infusion modulates systemic immunological responses in stable COPD patients: A phase I pilot study. European Respiratory Journal, 51(3), 1702369. https://doi.org/10. 1183/13993003.02369-2017.

31. Li, D., Liu, Q., Qi, L., Dai, X., Liu, H., \& Wang, Y. (2016). Low levels of TGF-beta1 enhance human umbilical cord-derived mesenchymal stem cell fibronectin production and extend survival time in a rat model of lipopolysaccharideinduced acute lung injury. Molcular Medicine Reports, 14(2), 1681-1692. https://doi.org/10. 3892/mmr.2016.5416.

32. Takeda, K., Ning, F., Domenico, J., Okamoto, M., Ashino, S., Kim, S. H., Jeong, Y. Y., Shiraishi, Y., Terada, N., Sutherland, E. R., \& Gelfand, E. W. (2018). Activation of p70S6 Kinase1 in mesenchymal stem cells is essential to lung tissue repair. Stem Cells Translated Medicine, 7(7), 551-558. https://doi.org/10.1002/sctm. 17-0200.
33. Varkouhi, A. K., Jerkic, M., Ormesher, L., Gagnon, S., Goyal, S., Rabani, R., Masterson, C., Spring, C., Chen, P. Z., Gu, F. X., dos Santos, C. C., Curley, G. F., \& Laffey, J. G. (2019). Extracellular vesicles from interferon- $\gamma$-primed human umbilical cord Mesenchymal stromal cells reduce Escherichia coli-induced acute lung injury in rats. Anesthesiology, 130(5), 778-790. https://doi. org/10.1097/ALN.0000000000002655.

34. Amann, E. M., Rojewski, M. T., Rodi, S., Furst, D., Fiedler, J., Palmer, A., et al. (2018). Systemic recovery and therapeutic effects of transplanted allogenic and xenogenic mesenchymal stromal cells in a rat blunt chest trauma model. Cytotherapy, 20(2), 218-231. https://doi.org/10.1016/j.jcyt.2017.11.005.

35. Wang, H., Yang, Y. F., Zhao, L., Xiao, F. J., Zhang, Q. W., Wen, M. L., Wu, C. T., Peng, R. Y., \& Wang, L. S. (2013). Hepatocyte growth factor gene-modified mesenchymal stem cells reduce radiation-induced lung injury. Human Gene Therapy, 24(3), 343353. https://doi.org/10.1089/hum.2012.177.

36. Lan, Y. W., Choo, K. B., Chen, C. M., Hung, T. H., Chen, Y. B., Hsieh, C. H., Kuo, H. P., \& Chong, K. Y. (2015). Hypoxiapreconditioned mesenchymal stem cells attenuate bleomycin induced pulmonary fibrosis. Stem Cell Research Therapy, 6, 97. https://doi.org/10.1186/s13287-015-0081-6.

37. Petrella, F., Coccè, V., Masia, C., Milani, M., Salè, E. O., Alessandri, G., Parati, E., Sisto, F., Pentimalli, F., Brini, A. T., Pessina, A., \& Spaggiari, L. (2017). Paclitaxel-releasing mesenchymal stromal cells inhibit in vitro proliferation of human mesothelioma cells. Biomedicine \& Pharmacotherapy, 87, 755-758. https:// doi.org/10.1016/j.biopha.2017.01.118.

38. Tobin, L. M., Healy, M. E., English, K., \& Mahon, B. P. (2013). Human mesenchymal stem cells suppress donor $\mathrm{CD} 4\left(^{+}\right) \mathrm{T}$ cell proliferation and reduce pathology in a humanized mouse model of acute graft-versus-host disease. Clinical and Experimental Immunology, 172(2), 333-348. https://doi.org/10.1111/cei.12056.

39. Yi, J. Z., Chen, Z. H., Xu, F. H., Wang, Z. Y., Zhang, H. Q., Jiang, G. S., \& Luan, X. Y. (2018). Interferon- $\gamma$ suppresses the proliferation and migration of human placenta-derived mesenchymal stromal cells and enhances their ability to induce the generation of $\mathrm{CD}^{+} \mathrm{CXCR}^{+} \mathrm{Foxp}^{+}$Treg subset. Cell Immunology, 326, 42-51. https://doi.org/10.1016/j.cellimm.2017.07.009.

40. Ren, G., Zhao, X., Zhang, L., Zhang, J., L'Huillier, A., Ling, W., Roberts, A. I., le, A. D., Shi, S., Shao, C., \& Shi, Y. (2010). Inflammatory cytokine-induced intercellular adhesion molecule-1 and vascular cell adhesion molecule-1 in mesenchymal stem cells are critical for immunosuppression. Journal of Immunology, 184(5), 2321-2328. https://doi.org/10.4049/jimmunol.0902023.

41. Krampera, M. (2011). Mesenchymal stromal cell 'licensing': A multistep process. Leukemia, 25(9), 1408-1414. https://doi.org/ 10.1038/leu.2011.108.

Publisher's Note Springer Nature remains neutral with regard to jurisdictional claims in published maps and institutional affiliations. 